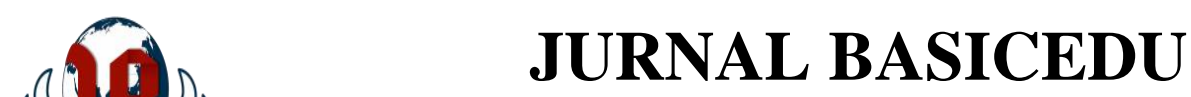

Volume 5 Nomor 3 Tahun 2021 Halaman 1169 - 1174

Research \& Learning in Elementary Education

https://jbasic.org/index.php/basicedu

PAHLAWAN

\title{
Analisis Faktor yang Mempengaruhi Manajemen Supervisi Akademik selama Pandemi COVID-19 di Kalimantan Barat
}

\author{
Herry Sanoto \\ Universitas Kristen Satya Wacana, Indonesia \\ E-mail: herry.sanoto@uksw.edu
}

\begin{abstract}
Abstrak
Kompetensi profesional guru sekolah dasar dipengaruhi oleh pelaksanaan supervisi akademik. Pandemi tidak hanya mempengaruhi daerah yang sudah maju, tetapi juga daerah tertinggal seperti Kabupaten Sanggau, Kalimantan Barat. Sebelum pandemi COVID-19, pelaksanaan supervisi akademik sudah menghadapi tantangan seperti keterbatasan jumlah pengawas, lokasi sekolah yang berjauhan, alokasi waktu untuk melakukan supervisi, dan biaya pelaksanaan supervisi. Atas dasar itu, perlu diketahui faktor-faktor yang mempengaruhi pelaksanaan supervisi akademik bagi guru sekolah dasar pada saat di daerah tertinggal selama pandemi, sehingga ada solusi untuk mengatasi permasalahan tersebut. Penelitian ini bertujuan untuk menganalisis faktor-faktor yang mempengaruhi pelaksanaan supervisi akademik guru sekolah dasar di Kabupaten Sanggau pada saat pandemi. Penelitian ini menggunakan metode kualitatif. Pengumpulan data dilakukan dengan wawancara dengan dinas pendidikan, kepala sekolah, pengawas sekolah dasar dan guru. Penelitian ini berhasil menemukan faktor-faktor yang mempengaruhi ketidakefektifan pembinaan akademik pada saat terjadi pandemi di Kabupaten Sanggau. Faktor-faktor tersebut adalah kebijakan pemerintah daerah terkait dengan pembatasan kegiatan tatap muka di sekolah dan pengalihan supervisi tatap muka pengawas dan guru ke supervisi online. Oleh karena itu, dapat disimpulkan faktor-faktor yang mempengaruhi manajemen supervisi akademik adalah kebijakan Pemerintah Daerah dan perubahan pola komunikasi.
\end{abstract}

Kata Kunci: Majemen Supervisi, Daerah Tertinggal, Pandemi.

\begin{abstract}
Elementary school teachers' professional competence is influenced by the implementation of academic supervision. The pandemic not only affects the developed regions, but also the underdeveloped areas, such as Sanggau District, West Kalimantan. Prior to the COVID-19 pandemic, the implementation of academic supervision was already faced with the limited number of supervisors, the diffusive locations of the elementary school, the time needed for the supervision, and the cost of implementing the supervision. On that basis, it is necessary to find out the factors that affect the implementation of academic supervision for elementary school teachers during the pandemic in underdeveloped areas, so that there will be a solution to overcome the problems. This study aims to analyze the factors that influence the implementation of academic supervision for elementary school teachers in Sanggau District during the pandemic. The study used a qualitative method by interviewing the education office, school principals, elementary school supervisors and teachers. The research was able to discover the factors that influence the ineffectiveness of the academic supervision during the pandemic in Sanggau District. The factors are local government policies related to restrictions on school activities which result in changes of the procedure to conduct academic supervision, so an education-oriented policy is necessary and communication patterns, face-to-face supervisors and teachers are not possible, it is shifted to IT based communication. In conclusion, the factors that influence the implementation of the management academic supervision model are 1) Local Government Policy, stage 2) governance of supervision implementation, and stage 3) Communication patterns.
\end{abstract}

Keywords: Supervision Management, Underdeveloped Area, Pandemic.

Copyright (c) 2021 Herry Sanoto

Corresponding author :

Email: : herry.sanoto@uksw.edu

DOI $\quad:$ https://doi.org/10.31004/basicedu.v5i3.858

ISSN 2580-3735 (Media Cetak)

ISSN 2580-1147 (Media Online)

Jurnal Basicedu Vol 5 No 3 Tahun 2021

p-ISSN 2580-3735 e-ISSN 2580-1147 
1170 Analisis Faktor yang Mempengaruhi Manajemen Supervisi Akademik selama Pandemi COVID-19 di Kalimantan Barat - Herry Sanoto

DOI: https://doi.org/10.31004/basicedu.v5i3.858

\section{PENDAHULUAN}

Sekolah memiliki tanggungjawab untuk mendidik generasi penerus demi masa depan negeri yang lebih baik. Untuk mewujudkan pendidikan yang lebih berkualitas tidaklah mudah, banyak faktor yang menghambat kelangsungan pembangunan pendidikan. Semua faktor tersebut harus dihadapi oleh sekolah sebagai garda terdepan lembaga pendidikan. Oleh karena itu, sekolah harus diawasi lewat supervisi untuk menjaga relevansinya agar dapat bertahan di dunia yang terus berubah ini. Dalam mengatasi berbagai permasalahan pendidikan, pemerintah di Indonesia telah melakukan banyak hal. Salah satunya peningkatan kompetensi sekolah dasar dengan memberikan supervisi. Adapun kegiatan yang dilakukan pemerintah untuk meningkatkan kualitas guru adalah supervisi, pelatihan, workshop, pemberian sertifikasi kepada guru, bahkan pemberian beasiswa bagi guru yang berprestasi dalam mengajar untuk lebih meningkatkan profesionalitasnya (Haimah, 2019). Diharapkan guru dapat meningkatkan kualitas proses pembelajaran sehingga siswa benarbenar mampu menguasai pembelajaran di sekolah.

Berbagai upaya telah dilakukan untuk meningkatkan mutu pendidikan, namun upaya tersebut belum memberikan pengaruh yang signifikan dalam meningkatkan mutu proses pembelajaran yang berlangsung di kelas (Prasetyono, Abdillah, \& Fitria, 2018). Hal ini disebabkan tidak hanya kondisi masing-masing sekolah dan kelas yang heterogen tetapi juga keterampilan atau kemampuan guru yang masih belum optimal. Di sinilah dibutuhkan pendampingan dari pengawas dan kepala sekolah untuk meningkatkan kualitas guru. Bersamaan dengan supervisi, guru diharapkan mendapatkan bimbingan, arahan, dan pelatihan yang terjadwal untuk meningkatkan profesionalitasnya dalam mengelola proses pembelajaran di dalam dan di luar kelas (Nababan, Ardani, \& Purba, 2020). Pengawas baik kepala sekolah maupun pengawas harus terus meningkatkan kompetensinya dalam melaksanakan supervisi pendidikan. Pengawasan yang berhasil sangat bergantung pada kemampuan supervisor untuk membentuk kelompok kerja yang kohesif di antara bawahannya melalui lima prinsip Human Relations School of thinking yaitu kerendahan hati, tanggung jawab, martabat manusia, keserasian, dan asumsi yang dapat diubah (Adu, Akinloye, \& Olaoye, 2014).

Dalam Kamus Inggris Indsonesia (Echols \& Shadily, 2000), supervision berarti pengawasan utama atau pengontrolan tinggi. Zakia, Sagala, \& Siburian (2017) memberikan pengertian bahwa secara umum supervisi berarti upaya bantuan yang diberikan kepada guru dalam melaksanakan tugas profesionalnya, sehingga guru mampu membantu siswa belajar menjadi lebih baik dari sebelumnya. Supervisi akademik menurut Glickman (1985) merupakan rangkaian kegiatan yang membantu guru mengembangkan kemampuannya dalam mengelola proses pembelajaran untuk pencapaian tujuan pembelajaran. Menurut Masaong \& Arsyad (2015) supervisi akademik adalah supervisi yang menitikberatkan pada pengamatan masalah akademik yang berkaitan langsung dengan ruang lingkup kegiatan pembelajaran pada saat siswa berada dalam proses pembelajaran.

Menurut Yuliana \& Arikunto (2008) prinsip supervisi akademik yang harus dipenuhi adalah: 1). Memberikan bantuan dan bimbingan kepada guru dalam mengatasi masalah dan kesulitan daripada mencari kesalahan. 2). Pemberian pendampingan dan pembinaan dilakukan secara langsung. 3). Memberi umpan balik langsung dari hasil supervisi. 4). Kegiatan pengawasan harus dilakukan secara rutin. 5). Suasana yang terjadi selama supervisi berlangsung hendaknya mencerminkan adanya hubungan baik antara pengawas dan guru. 6). Untuk menjaga agar apa yang dilakukan dan ditemukan tidak hilang atau dilupakan, supervisor harus menulis catatan singkat yang berisi poin-poin penting yang diperlukan untuk menyusun laporan. Supervisi akademik merupakan fungsi dari supervisi yang berkaitan dengan aspek pengembangan maupun pembinaan kemampuan profesional guru dalam upaya meningkatkan kualitas pembelajaran serta kegiatan bimbingan di sekolah.

Sasaran supervisi akademik dilakukan untuk membantu guru dalam: 1). Melakukan perencanaan kegiatan belajar dan atau bimbingan belajar, 2). Menilai proses dan hasil belajar / bimbingan, 3). 
1171 Analisis Faktor yang Mempengaruhi Manajemen Supervisi Akademik selama Pandemi COVID-19 di Kalimantan Barat - Herry Sanoto

DOI: https://doi.org/10.31004/basicedu.v5i3.858

Melaksanakan kegiatan belajar atau bimbingan, 4). Memanfaatkan hasil penilaian untuk meningkatkan pembelajaran atau layanan bimbingan, 5). Melayani siswa yang mengalami kesulitan mengajar, 6). Menciptakan lingkungan belajar yang bersahabat, 7). Memberikan umpan balik yang akurat dan teratur kepada siswa 8). Mengembangkan dan memanfaatkan alat multi media untuk pembelajaran dan, 9). Kembangkan interaksi pembelajaran yang sesuai dan efisien (metode, strategi, teknik, model, dan pendekatan), 10). Melakukan penelitian praktis untuk meningkatkan pembelajaran, dan 11). Mengembangkan inovasi pembelajaran. Arikunto (2006) mengemukakan bahwa tujuan umum supervisi akademik adalah memberikan bantuan teknis dan bimbingan kepada guru untuk meningkatkan kualitas kinerja pengajarannya. Indikator supervisi akademik meliputi: 1). Merencanakan program supervisi akademik, 2). Pelaksanaan supervisi akademik, 3). Bimbingan dalam supervisi, 4). Hasil pengawasan, 5). Tindak lanjut hasil supervisi dalam meningkatkan profesionalisme guru.

\section{METODE PENELITIAN}

Penelitian ini menggunakan metode kualitatif untuk mengumpulkan dan menganalisis data. Menurut Creswell (2015), penelitian metode kualitatif adalah penelitian yang mengumpulkan dan menganalisis data berbasis teks yang dikumpulkan dengan menggunakan wawancara dan catatan observasi. Metode kualitatif mencakup langkah-langkah di mana peneliti mengumpulkan dan menganalisis data wawancara dan catatan observasi secara berurutan dan / atau bersamaan yang mengintegrasikan data berbasis teks. Cara penggabungan data ini akan bergantung pada sifat penyelidikan dan pandangan filosofis orang yang melakukan penelitian. Metode tersebut memungkinkan tingkat pemahaman yang lebih baik untuk dirumuskan daripada menggunakan hanya satu metode penelitian.

Partisipan penelitian ini adalah lima belas guru sekolah dasar. Penelitian difokuskan pada penerapan manajemen pengawasan di Kabupaten Sanggau, daerah terpencil di Kalimantan Barat, saat terjadi pandemi. Instrumen pengumpulan data adalah wawancara semi terstruktur dan observasi langsung. Wawancara semiterstruktur dipilih karena fleksibilitasnya yang diberikan dan menyediakan ruang untuk menghasilkan pertanyaan. Sedangkan observasi langsung digunakan untuk membatasi gangguan pengawas, kepala sekolah, dan guru selama supervisi dilaksanakan.

Analisis data meliputi interpretasi transkrip wawancara dan catatan lapangan yang dihasilkan dari observasi. Transkrip wawancara dan catatan observasi dikumpulkan dan diklasifikasikan ke dalam kategori. Tujuannya untuk mengetahui faktor-faktor yang mempengaruhi pelaksanaan manajemen pengawasan pada saat terjadi pandemi di Kabupaten Sanggau. Penelitian ini menggunakan analisis tematik karena merupakan metode yang fleksibel untuk menyimpulkan hasil penelitian. Menurut Braun \& Clarke (2012), analisis tematik adalah metode sistematis untuk mengidentifikasi, mengatur, dan menawarkan wawasan tentang tema di seluruh kumpulan data. Ini juga merupakan metode yang fleksibel untuk fokus pada data dengan berbagai cara. Karena datanya dalam bentuk persentase dan teks, maka diperlukan keleluasaan dalam menganalisis data.

\section{HASIL DAN PEMBAHASAN}

Berdasarkan hasil wawancara dan observasi dapat disimpulkan bahwa faktor-faktor yang mempengaruhi pelaksanaan supervisi akademik adalah kebijakan pemerintah daerah dan perubahan pola komunikasi. 
1172 Analisis Faktor yang Mempengaruhi Manajemen Supervisi Akademik selama Pandemi COVID-19 di Kalimantan Barat - Herry Sanoto

DOI: https://doi.org/10.31004/basicedu.v5i3.858

\section{Kebijakan Pemerintah Daerah}

Kebijakan pemerintah daerah terkait dengan pembatasan kegiatan sekolah yang mengakibatkan perubahan tata cara penyelenggaraan supervisi akademik, sehingga diperlukan kebijakan yang berorientasi pada pendidikan. Selama pandemi, pemerintah membuat kebijakan untuk membatasi interaksi tatap muka untuk meratakan kurva. Namun, tak mudah bagi mereka yang tinggal di daerah terpencil seperti Kabupaten Sanggau. Penerapan restriksi sosial skala besar menjadi tantangan baru bagi pengawas, kepala sekolah, dan guru untuk melakukan supervisi.

Menurut Arikunto (2006) indikator supervisi adalah pelaksanaan supervisi dan pembinaan akademik. Termasuk evaluasi bagi kepala sekolah dan guru untuk meningkatkan profesionalitas kerja. Supervisi akademik di Kabupaten Sanggau dulunya dilakukan secara tatap muka yang tidak mungkin dilakukan pada saat pandemi. Oleh karena itu, mereka harus menggunakan platform online untuk melakukan pengawasan. Akan tetapi, data untuk pengawasan tersebut hanya berdasarkan dokumen yang telah diserahkan karena tidak memungkinkan untuk dilakukan pengawasan langsung oleh pengawas. Dengan demikian, masukan yang diberikan kepada kepala sekolah dan guru kurang efektif untuk menilai profesionalitasnya.

Di sisi lain, pengawasan terhadap guru oleh kepala sekolah masih bisa dilakukan secara tatap muka saat pandemi karena guru masih harus datang ke sekolah untuk mengajar siswanya secara online. Namun berdasarkan wawancara dan observasi, terlihat jelas bahwa supervisi guru yang diberikan oleh kepala sekolah kebanyakan bias karena guru adalah rekan kerja mereka. Dengan demikian, kepala sekolah mungkin merasa tidak enak jika mereka mengkritik rekan kerja mereka. Menurut Yuliana \& Arikunto (2008) kepala sekolah harus memberikan pendampingan dan pembinaan secara langsung tanpa harus memaksa guru. Pengawasan harus substansial bagi para guru untuk meningkatkan profesionalitasnya. Oleh karena itu, kepala sekolah hendaknya memberikan pengawasan berdasarkan fakta daripada merasa tidak enak mengkritik rekan kerjanya.

\section{Perubahan Pola Komunikasi}

Selama pandemi, pengawasan tatap muka tidak memungkinkan. Oleh karena itu, pengawasan sekolah harus dialihkan dengan platform online. Karena Kabupaten Sanggau termasuk daerah tertinggal, sulit bagi sekolah untuk beralih ke pengawasan online. Koneksi internet menjadi masalah utama selama pengawasan. Mereka tidak dapat menggunakan telekonferensi seperti Google Meet atau Zoom selama pengawasan. Pengawas mengandalkan dokumen yang dikirim sekolah menggunakan email. Sehingga evaluasi yang dilakukan hanya berdasarkan RPP dan supervisi kepala sekolah yang biasanya bias.

Manajemen supervisi akademik di Sanggau belum disesuaikan dengan kondisi kegiatan sekolah pada saat pandemi. Sebelum pandemi, pengawasan sekolah sudah cukup sulit karena jarak antar sekolah di Kabupaten Sanggau yang jauh dan sulit dijangkau. Meski pengawasan rutin sudah sulit dilakukan karena infrastruktur yang belum berkembang, pandemi membuat proses pengawasan menjadi lebih sulit.

Bersamaan dengan kebijakan pemerintah memberlakukan pembatasan sosial berskala besar, proses pengawasan harus bisa beradaptasi dalam melakukan pengawasan yang efektif. Menurut Arikunto (2006), pengawas harus mampu membantu guru dalam mengembangkan strategi dalam pembelajaran yang tepat dan efisien serta melakukan analisa kebutuhan pembelajaran di kelas. Hal ini akan lebih mudah diimplementasikan jika pengawas dapat mengunjungi sekolah, tetapi tidak memungkinkan karena pandemi. Oleh karena itu, proses pengawasan dipaksa untuk tetap relevan dan adaptif selama pandemi. Pergeseran pengawasan menggunakan platform online merupakan strategi yang paling relevan untuk mengatasi masalah tersebut.

Menurut Yuliana \& Arikunto (2008) supervisi akademik harus menilai proses dan hasil belajar untuk meningkatkan layanan pembelajaran. Asesmen tidak dapat dilaksanakan secara efektif karena pengawas tidak 
1173 Analisis Faktor yang Mempengaruhi Manajemen Supervisi Akademik selama Pandemi COVID-19 di Kalimantan Barat - Herry Sanoto

DOI: https://doi.org/10.31004/basicedu.v5i3.858

mengetahui proses pembelajaran melalui observasi langsung di sekolah. Dokumen tersebut hanya memuat RPP dan lembar evaluasi guru yang kurang memadai untuk mengevaluasi guru. Untuk mengatasi masalah tersebut, pemerintah perlu membangun infrastruktur agar proses pengawasan sekolah dapat berjalan efektif.

\section{KESIMPULAN}

Pandemi tersebut telah membawa banyak gangguan dalam bidang pendidikan, termasuk di pelosok Kabupaten Sanggau, Kalimantan Barat. Saat ini, social distancing menjadi suatu keharusan yang menimbulkan tantangan baru dalam pengawasan sekolah di daerah terpencil. Padahal sebelum pandemi supervisi akademik di Kabupaten Sanggau sudah dihadapkan pada keterbatasan jumlah pengawas, lokasi SD yang tersebar, waktu yang dibutuhkan untuk supervisi, dan mahalnya biaya supervisi langsung di sekolah. Pandemi membuat proses pengawasan menjadi lebih sulit dari sebelumnya. Penelitian ini berhasil menemukan faktor-faktor yang mempengaruhi ketidakefektifan pembinaan akademik pada saat terjadi pandemi di Kabupaten Sanggau. Faktor-faktor tersebut adalah 1) kebijakan pemerintah daerah terkait dengan pembatasan kegiatan sekolah yang mengakibatkan perubahan tata cara penyelenggaraan supervisi akademik, sehingga diperlukan kebijakan yang berorientasi pada pendidikan, 2) pihak manajemen untuk melakukan supervisi akademik yang belum disesuaikan dengan kondisi. kegiatan sekolah pada masa pandemi, sehingga diperlukan supervisi yang adaptif, dan 3) pola komunikasi, tatap muka pengawas dan guru tidak memungkinkan, maka dialihkan ke komunikasi berbasis IT. Kebijakan pemerintah daerah terkait pembatasan kegiatan sekolah yang mengubah tata cara melakukan supervisi akademik. Selama pandemi, pemerintah membatasi interaksi tatap muka untuk meratakan kurva. Namun, tak mudah bagi mereka yang tinggal di daerah terpencil seperti Kabupaten Sanggau. Penerapan restriksi sosial skala besar menjadi tantangan baru bagi pengawas, kepala sekolah, dan guru untuk melakukan supervisi. Ini memaksa mereka menggunakan platform online untuk melakukan pengawasan. Di sisi lain, pihak manajemen melakukan supervisi akademik yang belum disesuaikan dengan kondisi kegiatan sekolah saat terjadi pandemi. Sebelum pandemi, pengawasan sekolah ditantang untuk tetap relevan dan adaptif. Jarak antar sekolah di Kabupaten Sanggau cukup jauh dan sulit dijangkau. Meski pengawasan rutin sudah sulit dilakukan karena infrastruktur yang belum berkembang, pandemi membuat proses pengawasan menjadi lebih sulit. Dengan demikian, pengawasan langsung dan langsung menggunakan telekonferensi tidak dimungkinkan karena keterbatasan infrastruktur. Selama pandemi, pengawasan kunjungan sekolah tidak memungkinkan. Oleh karena itu, pengawasan sekolah harus dialihkan ke platform online. Karena Kabupaten Sanggau termasuk daerah tertinggal, sulit bagi sekolah untuk memiliki koneksi internet yang layak yang menjadi kendala utama dalam pengawasan. Mereka tidak dapat menggunakan telekonferensi seperti Google Meet atau Zoom selama pengawasan. Pengawas mengandalkan dokumen yang dikirim sekolah menggunakan email. Sehingga evaluasi yang dilakukan hanya berdasarkan RPP dan supervisi kepala sekolah yang biasanya bias. Penelitian ini mencoba membantu pemerintah daerah untuk menganalisis faktor-faktor yang mempengaruhi pelaksanaan pengawasan di Kabupaten Sanggau, Kalimantan Barat. Kajian dibatasi pada beberapa bagian meskipun memberikan beberapa temuan dan pembahasan. Hasil studi ini tidak bisa digeneralisasikan untuk semua masalah pengawasan daerah terpencil. Oleh karena itu, untuk penelitian selanjutnya sebaiknya menggunakan partisipan yang lebih besar agar hasil penelitiannya menjadi lebih detail.

\section{DAFTAR PUSTAKA}

Adu, E. O., Akinloye, G. M., \& Olaoye, O. F. (2014). Internal and external school supervision: Issues, challenges and wayforward. International Journal of Educational Sciences, 7(2), 269-278.

Arikunto, S. (2006). Metodelogi penelitian. Yogyakarta: Bina Aksara. 
1174 Analisis Faktor yang Mempengaruhi Manajemen Supervisi Akademik selama Pandemi COVID-19 di Kalimantan Barat - Herry Sanoto

DOI: https://doi.org/10.31004/basicedu.v5i3.858

Braun, V., \& Clarke, V. (2012). Thematic analysis.

Creswell, J. W. (2015). A concise introduction to mixed methods research. Retrieved from https://books.google.com.au/books/about/A_Concise_Introduction_to_Mixed_Methods.html?id=KeyRA wAAQBAJ\&pgis $=1$

Echols, J. M., \& Shadily, H. (2000). Kamus Inggris Indonesia, cet. ke-25. Jakarta: Gramedia.

Glickman, C. D. (1985). Supervision of instruction: A developmental approach. ERIC.

Haimah, H. (2019). Academic Supervision by School Principals at State Elementary Schools in Indonesia. International Conference on Educational Sciences and Teacher Profession (ICETeP 2018), 34-37. Atlantis Press.

Masaong, A. K., \& Arsyad, A. (2015). ANALISIS KOMPETENSI PENGAWAS DALAM IMPLEMENTASI MANAJEMEN BERBASIS SEKOLAH MELALUI PENGUATAN BUDAYA MUTU SEKOLAH MENENGAH PERTAMA DI KABUPATEN BOALEMO. Seminar Nasional Riset Inovatif, 3.

Nababan, T. M., Ardani, S., \& Purba, S. (2020). Educational Supervision to Increase Teacher Professionalism in The 21st Century Learning Era.

Prasetyono, H., Abdillah, A., \& Fitria, D. (2018). Academic supervision toward teacher's performance through motivation as intervening variable. Journal of Education and Learning (EduLearn), 12(2), 188197.

Yuliana, L., \& Arikunto, S. (2008). Manajemen Pendidikan. Yogyakarta: Teras.

Zakia, S., Sagala, H. S., \& Siburian, P. (2017). Improving The Ability of State Vocational High School Teachers in Creating Digital StoryTelling Media (DST) Using Sway Microsoft Tool Through Academic Supervision of Demonstration Technique. 2nd Annual International Seminar on Transformative Education and Educational Leadership (AISTEEL 2017), 251-255. Atlantis Press. 